Article

\title{
Human Lanosterol 14-Alpha Demethylase (CYP51A1) Is a Putative Target for Natural Flavonoid Luteolin 7,3'-Disulfate
}

\author{
Leonid Kaluzhskiy ${ }^{1, *}$, Pavel Ershov ${ }^{1}$, Evgeniy Yablokov ${ }^{1}{ }^{\mathbb{D}}$, Tatsiana Shkel ${ }^{2}$, Irina Grabovec ${ }^{2}$, Yuri Mezentsev ${ }^{1}$, \\ Oksana Gnedenko ${ }^{1}\left(\mathbb{D}\right.$, Sergey Usanov ${ }^{2}$, Polina Shabunya ${ }^{2}$, Sviatlana Fatykhava ${ }^{2}$, Alexander Popov ${ }^{3}$, \\ Aleksandr Artyukov ${ }^{3}$, Olga Styshova ${ }^{3}$, Andrei Gilep ${ }^{2}$, Natallia Strushkevich ${ }^{4, *}$ and Alexis Ivanov ${ }^{1}$
}

1 Institute of Biomedical Chemistry, 10 Building 8, Pogodinskaya Street, 119121 Moscow, Russia; pavel.ershov@ibmc.msk.ru (P.E.); evgeniy.yablokov@ibmc.msk.ru (E.Y.); yuri.mezentsev@ibmc.msk.ru (Y.M.); oksana@ibmh.msk.su (O.G.); alexei.ivanov@ibmc.msk.ru (A.I.)

2 Institute of Bioorganic Chemistry NASB, 5 Building 2, V.F. Kuprevich Street, 220141 Minsk, Belarus; tvshkel@gmail.com (T.S.); grabovec-irina@mail.ru (I.G.); usanov@iboch.by (S.U.); iboh_lfhi@rambler.ru (P.S.); fsa1981@tut.by (S.F.); agilep@iboch.by (A.G.)

3 G.B. Elyakov Pacific Institute of Bioorganic Chemistry, Far Eastern Branch of the Russian Academy of Science, 159 Prospect 100-letiya Vladivostoka, 690022 Vladivostok, Russia; popovam@piboc.dvo.ru (A.P.); artyukova@mail.ru (A.A.); krivoshapkoon@mail.ru (O.S.)

4 Skolkovo Institute of Science and Technology, Bolshoy Boulevard 30, bld. 1, 121205 Moscow, Russia

* Correspondence: leonid.kaluzhskiy@ibmc.msk.ru (L.K.); n.strushkevich@skoltech.ru (N.S.)

Citation: Kaluzhskiy, L.; Ershov, P.; Yablokov, E.; Shkel, T.; Grabovec, I.; Mezentsev, Y.; Gnedenko, O.; Usanov, S.; Shabunya, P.; Fatykhava, S.; et al. Human Lanosterol 14-Alpha Demethylase (CYP51A1) Is a Putative Target for Natural Flavonoid Luteolin 7,3'-Disulfate. Molecules 2021, 26, 2237. https://doi.org/10.3390/ molecules 26082237

Academic Editor:

Celestino Santos-Buelga

Received: 10 March 2021

Accepted: 12 April 2021

Published: 13 April 2021

Publisher's Note: MDPI stays neutral with regard to jurisdictional claims in published maps and institutional affiliations.

Copyright: (c) 2021 by the authors. Licensee MDPI, Basel, Switzerland. This article is an open access article distributed under the terms and conditions of the Creative Commons Attribution (CC BY) license (https:// creativecommons.org/licenses/by/ $4.0 /)$.

\begin{abstract}
Widespread pathologies such as atherosclerosis, metabolic syndrome and cancer are associated with dysregulation of sterol biosynthesis and metabolism. Cholesterol modulates the signaling pathways of neoplastic transformation and tumor progression. Lanosterol 14-alpha demethylase (cytochrome P450(51), CYP51A1) catalyzes one of the key steps in cholesterol biosynthesis. The fairly low somatic mutation frequency of CYP51A1, its druggability, as well as the possibility of interfering with cholesterol metabolism in cancer cells collectively suggest the clinical importance of CYP51A1. Here, we show that the natural flavonoid, luteolin 7,3'-disulfate, inhibits CYP51A1 activity. We also screened baicalein and luteolin, known to have antitumor activities and low toxicity, for their ability to interact with CYP51A1. The $\mathrm{K}_{\mathrm{d}}$ values were estimated using both a surface plasmon resonance optical biosensor and spectral titration assays. Unexpectedly, in the enzymatic activity assays, only the water-soluble form of luteolin-luteolin 7,3'-disulfate-showed the ability to potently inhibit CYP51A1. Based on molecular docking, luteolin 7,3'-disulfate binding suggests blocking of the substrate access channel. However, an alternative site on the proximal surface where the redox partner binds cannot be excluded. Overall, flavonoids have the potential to inhibit the activity of human CYP51A1 and should be further explored for their cholesterol-lowering and anti-cancer activity.
\end{abstract}

Keywords: lanosterol 14-alpha demethylase; flavonoids; enzyme inhibition; surface plasmon resonance; spectral titration; molecular docking

\section{Introduction}

Cholesterol is a major source of bioactive sterols. Cholesterol modulates the signaling pathways of neoplastic transformation and tumor progression by covalently modifying hedgehog and smoothened family proteins [1,2] and it is also involved in atherosclerosis and metabolic syndrome progression [3]. Tumor growth is accompanied by a significant increase in the expression level of cholesterol biosynthetic enzymes, including lanosterol 14-alpha demethylase (cytochrome P450(51), CYP51A1) [4]. CYP51A1 belongs to the evolutionarily conserved family of cytochrome P450 and catalyzes the oxidative removal of the alpha-methyl group at the C14-position of the steroid substrate in three steps [5]. According to the COSMIC (http:/ / cancer.sanger.ac.uk/cosmic accessed on 29 June 2020) 
resource, the CYP51A1 gene has a fairly low somatic mutation frequency $(<0.1 \%)$ in various cancers. It has been shown that CYP51A1 gene expression correlates with the estrogen and progesterone receptor status of breast cancer [6] and could be one of the factors in assessing the survival rate of patients with gastric adenocarcinoma [7]. CYP51A1 catalyzes the production of 4,4-dimethyl-5 $\alpha$-cholesta-8,14,24-triene-3 $\beta$-ol (follicular fluid meiosisactivating sterol, FF-MAS), one of the modulators of meiosis [8]. The ploidy disturbance characteristic for cancer cells is caused by processes similar to meiosis [9]. Thus, FF-MAS might be linked to the ploidy balance of tumor cells. CYP51A1 gene knockout blocked de novo cholesterol synthesis [10], while CYP51A1 inhibition led to the induction of apoptosis in cancer cells [11], indicating the clinical significance of this protein.

We analyzed the potential of natural flavonoids (Figure 1) as modulators of CYP51A1 function using purified human protein. Baicalein and luteolin are flavonoids that were originally isolated from plants of the Scutellaria and Reseda genus. The inhibitory activity of baicalein and luteolin was demonstrated for some cytochrome P450 isozymes [12-14]. Baicalein exhibited broad antifungal activity [15] and demonstrated strong synergy with fluconazole [16], a known inhibitor of fungal CYP51A1. Luteolin possesses an antibacterial effect in vivo, increasing membrane permeability [17], but does not directly perturb the model membranes in vitro $[18,19]$. Both baicalein and luteolin possess antitumor activity $[20,21]$ and, as well as their derivatives, have been used in preclinical studies and in experimental oncology [22-27]. Epidemiological studies showed that foods rich in polyphenolic compounds (flavonoids, phenolic acids, lignans and stilbenes) included in the diet reduced the total risk of cancer by up to $50 \%$ [28]. Overall, 14 clinical trials were initiated to study baicalein and luteolin as dietary supplements (https:/ / clinicaltrials.gov/, accessed on 1 March 2021). The G.B. Elyakov Pacific Institute of Bioorganic Chemistry has a broad collection of natural compounds from unique Far-Eastern plants and marine species with a wide range of biological activities. Luteolin 7,3'-disulfate, a water-soluble luteolin derivative originally obtained from the seagrass Zostera marina [29], also exhibits antitumor activity $[30,31]$. It was shown that sulfation at the 7-position of the luteolin molecule decreases cytotoxicity [32]. Moreover, the activity of luteolin 7,3'-disulfate in some cases is stronger than that of luteolin $[30,33,34]$, possibly due to bypassing the stage of conjugation by intestinal and liver cells. Cholesterol is a crucial component of membranes, maintaining their permeability and fluidity. We hypothesized that flavonoids might target its synthesis via CYP51A1 and selected baicalein, luteolin and luteolin 7,3'-disulfate for testing. Using surface plasmon resonance (SPR), we showed that only luteolin 7,3'-disulfate interacted with CYP51A1 with high affinity. However, in the spectral binding experiments luteolin $7,3^{\prime}$-disulfate does not induce spectral changes. In contrast, baicalein and luteolin induce a reverse type I response in the difference absorption spectra of CYP51A1, indicating changes around heme iron. In the reconstituted enzymatic assay, among the three tested flavonoids, only luteolin 7,3'-disulfate inhibited the lanosterol $14 \alpha$-demethylase activity of human CYP51A1 with significant potency. The binding mode distant from the heme was predicted for luteolin 7,3'-disulfate by the performed molecular docking, showing the binding not in the hydrophobic active site but rather in the access channel. The inhibitory effect of the most hydrophilic form of tested flavonoids-luteolin 7,3'-disulfate-is quite unusual. We suggest that, besides the predicted binding, luteolin $7,3^{\prime}$-disulfate could also bind to the proximal surface of CYP51A1, interfering with the interaction to the redox partner. The obtained data open up a new valuable source of flavonoid modulators of CYP51A1 activity as an alternative to the classic inhibition by azole compounds. 
<smiles>O=c1cc(-c2ccccc2)oc2cc(O)c(O)c(O)c12</smiles>

Baicalein<smiles>O=c1cc(-c2ccc(O)c(O)c2)oc2cc(O)cc(O)c12</smiles>

Luteolin<smiles>COc1cc(O)c2c(=O)cc(-c3ccc(O)c(O)c3)oc2c1</smiles>

Luteolin 7,3'-disulfate

Figure 1. Flavonoids used in this work.

\section{Results}

\subsection{Surface Plasmon Resonance}

The CYP51A1 complex formation with flavonoids was detected using a SPR-biosensor. Lanosterol was used as a positive control to confirm the ability of immobilized CYP51A1 to bind ligands. With the CYP51A1 immobilized on the biosensor chip surface, we were able to detect the interaction with baicalein, luteolin and luteolin 7,3'-disulfate (Figure 2).
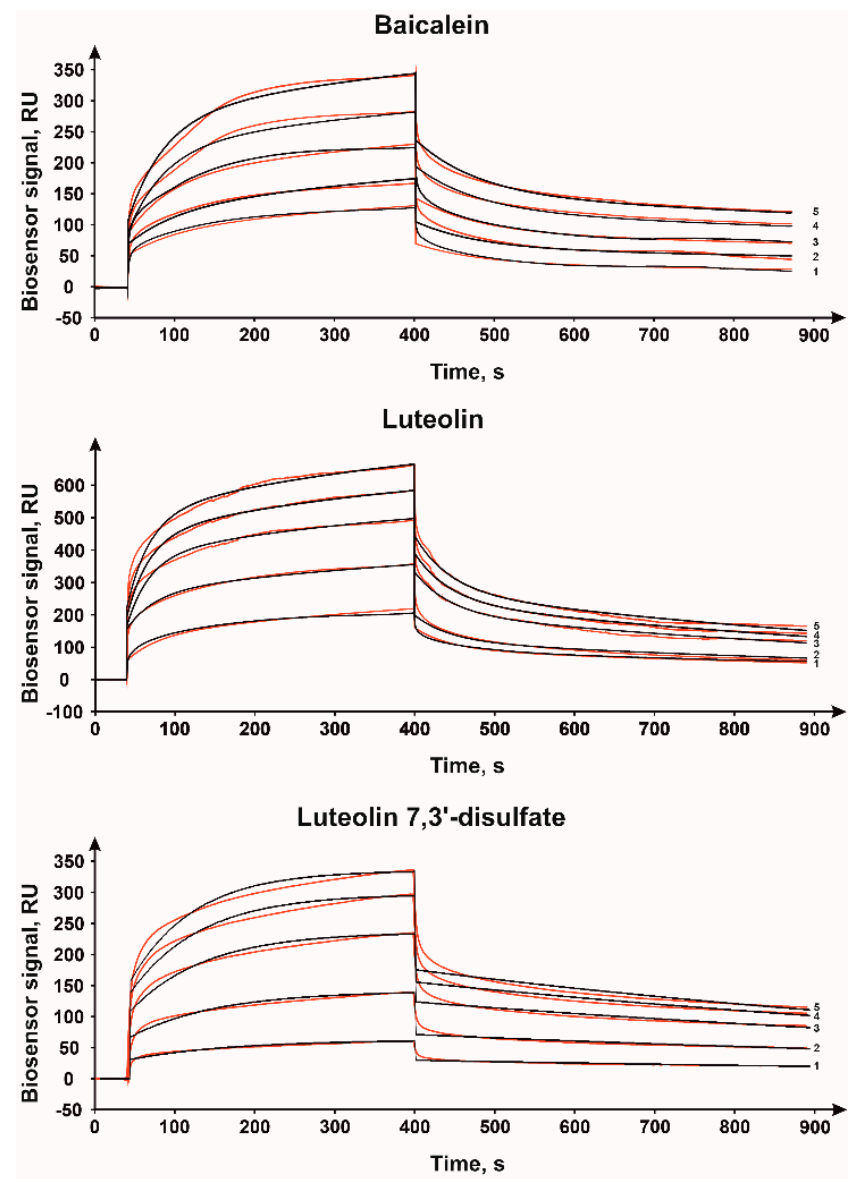

Figure 2. Typical surface plasmon resonance sensorgrams of binding between immobilized CYP51A1 on the optical chip and baicalein, luteolin and luteolin 7,3'-disulfate at different concentrations: 10 (1), 25 (2), 50 (3), 75 (4) and $100 \mu \mathrm{M}$ (5). Fitting curves (theoretical models) are highlighted in black; $\mathrm{Chi}^{2}=25.3$ (baicalein), 68.2 (luteolin), 10.2 (luteolin $7,3^{\prime}$-disulfate).

The equilibrium dissociation constant $\left(\mathrm{K}_{\mathrm{d}}\right)$ values of CYP51A1/flavonoid complexes were in the range of 2.9-20 $\mu \mathrm{M}$, calculated association and dissociation rate constants are shown in Table 1. The obtained Kd value of the CYP51A1/lanosterol complex was $2.4 \mu \mathrm{M}$, which is comparable with the previously published data [35]. The association rate of the CYP51A1 complex with luteolin 7,3'-disulfate is seven times faster compared 
to the complex formation with lanosterol, while the dissociation rate is about eight times higher. The resulting $\mathrm{K}_{\mathrm{d}}$ value for both complexes is similar. CYP51A1 complex formation with baicalein and luteolin is characterized by the increased association rate compared to lanosterol, but the main differences in the resulting $K_{d}$ value are due to the great increase in dissociation rates of the complexes. Overall, the binding of flavonoids is faster compared to the natural substrate, but the dissociation of the complexes is faster as well. The highest affinity was detected for luteolin $7,3^{\prime}$-disulfate, which is more soluble.

Table 1. Kinetic and equilibrium parameters of cytochrome P450(51) (CYP51A1) complex formation with lanosterol, baicalein, luteolin and luteolin 7,3'-disulfate.

\begin{tabular}{ccccc}
\hline Compound & $\mathbf{k}_{\text {on }}$ & $\mathbf{k}_{\text {off }}$ & $\mathbf{K}_{\mathrm{d}}, \boldsymbol{\mu M}$ & Evaluation Model \\
\hline lanosterol & $\mathrm{k}_{\text {on }}(1 / \mathrm{Ms})=41.4 \pm 5.0$ & $\mathrm{k}_{\text {off }}\left(1 / \mathrm{s} \times 10^{-4}\right)=1.0 \pm 0.2$ & 2.4 & Langmuir 1:1 \\
\hline baicalein & $\begin{array}{c}\mathrm{k}_{\text {on } 1}(1 / \mathrm{Ms})=146 \pm 20 \\
\mathrm{k}_{\text {on2 }}\left(1 / \mathrm{s} \times 10^{-4}\right)=27 \pm 3\end{array}$ & $\begin{array}{c}\mathrm{k}_{\text {off1 }}\left(1 / \mathrm{s} \times 10^{-4}\right)=100 \pm 20 \\
\mathrm{k}_{\text {off2 }}\left(1 / \mathrm{s} \times 10^{-4}\right)=6 \pm 1\end{array}$ & $\begin{array}{c}12.5 \\
\text { Two state reaction }\end{array}$ \\
\hline \multirow{2}{*}{ luteolin } & $\begin{array}{c}\mathrm{k}_{\text {on1 } 1}(1 / \mathrm{Ms})=282 \pm 40 \\
\mathrm{k}_{\text {on2 }}\left(1 / \mathrm{s} \times 10^{-4}\right)=33 \pm 4\end{array}$ & $\begin{array}{c}\mathrm{k}_{\text {off1 }}\left(1 / \mathrm{s} \times 10^{-4}\right)=190 \pm 30 \\
\mathrm{k}_{\text {off2 }}\left(1 / \mathrm{s} \times 10^{-4}\right)=14 \pm 2\end{array}$ & 20.0 & Two state reaction \\
\hline luteolin $7,3^{\prime}$-disulfate & $\mathrm{k}_{\text {on }}(1 / \mathrm{Ms})=294.0 \pm 32.3$ & $\mathrm{k}_{\text {off }}\left(1 / \mathrm{s} \times 10^{-4}\right)=8.4 \pm 2.0$ & 2.9 & Langmuir 1:1 \\
\hline
\end{tabular}

The table shows the average values of the parameters \pm standard deviation, $\mathrm{n}=3$.

\subsection{Spectral Titration Analysis}

The difference spectra of CYP51A1 were obtained by titration with baicalein, luteolin and luteolin 7,3'-disulfate in the presence of lanosterol. Baicalein and luteolin induced a reverse type I spectral response with absorbance minimum at $390 \mathrm{~nm}$ and maximum at $420 \mathrm{~nm}$ for luteolin and $436 \mathrm{~nm}$ for baicalein (Figure 3). These spectral changes are consistent with the previously detected interaction of cytochrome P450 1B1 with compounds of flavonoid class [36]. Titration with luteolin 7,3'-disulfate (up to $30 \mu \mathrm{M}$ ) does not cause changes in the difference spectrum of CYP51A1. The apparent dissociation constant $\left(\mathrm{K}_{\mathrm{dapp}}\right)$ values of the complexes of CYP51A1 with baicalein and luteolin were $8.2 \pm 0.4$ and $5.1 \pm 0.5 \mu \mathrm{M}$, respectively. It should be noted that the $\mathrm{K}_{\mathrm{d}}$ values from spectrophotometric titration experiments differ from those obtained using SPR. These differences can be attributed to the different affinities of the complexes in solution and immobilized on the surface of the optical chip. Interaction with the different sites of the enzyme cannot be excluded during SPR measurements and the measured $\mathrm{Kd}$ reflects all possible interactions between the ligand and enzyme, while spectral assays detect interactions of ligand only within close vicinity of the heme cofactor buried in the CYP active site.
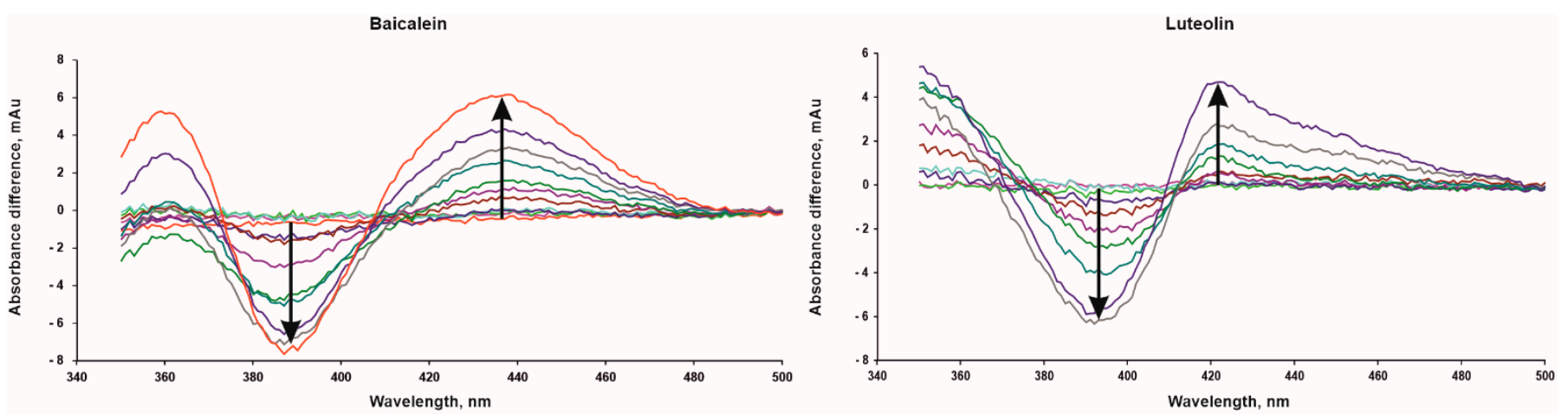

Figure 3. Difference spectra of CYP51A1 in the presence of lanosterol after addition of baicalein (up to $30 \mu \mathrm{M}$ ) and luteolin (up to $15 \mu \mathrm{M}$ ). The arrows indicate the direction of the spectral changes with increasing ligand concentration. 


\subsection{Enzyme Activity Assay}

Lanosterol $14 \alpha$-demethylase activity of human CYP51A1 in the presence of flavonoids was determined in the reconstituted system. Only luteolin 7,3'-disulfate can inhibit the activity of the CYP51A1 (Table 2). Surprisingly, luteolin, being a more hydrophobic molecule compared to its sulfated derivative, does not have a similar effect. The apparent IC50 for luteolin $7,3^{\prime}$-disulfate is greater than $25 \mu \mathrm{M}$. At the same time, the level of inhibition by ketoconazole $(94.6 \%$ at a concentration of compound of $5 \mu \mathrm{M})$ significantly exceeds the effect of luteolin $7,3^{\prime}$-disulfate ( $50.1 \%$ at a concentration of compound of $\left.25 \mu \mathrm{M}\right)$. Overall, the inhibition of CYP51A1 utilizing highly hydrophobic substrate by the water-soluble luteolin 7,3'-disulfate could not be predicted. This observation suggests a different mode of binding in the active site. To visualize the binding of luteolin and its disulfate in the active site we performed molecular docking.

Table 2. Effect of compounds on catalytic activity of human CYP51A1 (lanosterol 14 $\alpha$-demethylase) in the reconstituted system in vitro.

\begin{tabular}{cc}
\hline Compound & Relative Activity, $\%$ \\
\hline No compound & 100.0 \\
Baicalein $(25 \mu \mathrm{M})$ & 89.4 \\
Luteolin $(25 \mu \mathrm{M})$ & 92.6 \\
Luteolin $7,3^{\prime}$-disulfate $(25 \mu \mathrm{M})$ & 49.9 \\
Ketoconazole $(5 \mu \mathrm{M})$ & 5.4 \\
\hline
\end{tabular}

The final concentrations of CYP51A1 and cytochrome P450 reductase (CPR) were 0.5 and $2.0 \mu \mathrm{M}$, respectively. The final concentration of lanosterol was $50 \mu \mathrm{M}$.

\subsection{Molecular Docking}

We used a CYP51A1 crystal structure Protein Data Bank (PDB) ID: 3LD6 for molecular docking. The resulting models were selected based on the higher values of scoring function. The obtained docking poses are shown in Figure 4. Based on the docking results, luteolin binds very close to the heme coordinating iron (less than $3 \AA$ ) by the 3-OH-group of the phenyl ring. In contrast, luteolin 7, $3^{\prime}$-disulfate binds at $>8.5 \AA$ from the heme. The docking results are consistent with the spectral titration data-luteolin induces reverse type I spectra, while luteolin 7,3'-disulfate does not change the spectral response.
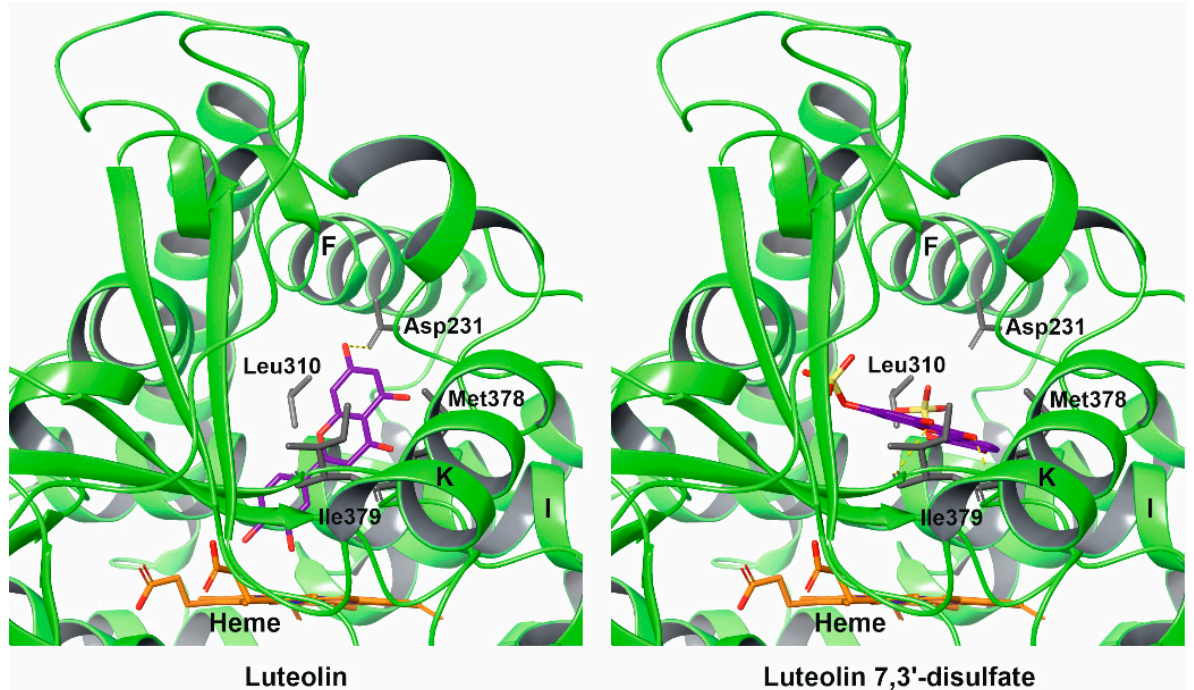

Figure 4. Luteolin and luteolin 7,3'-disulfate docked to the active site of human CYP51A1. The secondary structure of the protein is depicted as a ribbon and colored green. The amino acid side chains are shown as sticks and are colored in grey. The flavonoids and heme are shown as sticks and are colored in magenta and orange, respectively. 
Asp231 (C-terminal part of the F-helix) H-bonded to luteolin and is important for the enzymatic activity of CYP51 [37]. The negative charge in this position is highly conserved in Prokaryotes and Eukaryotes [38]. Residues Leu310 (part of I-helix), Met378 and Ile379 (both K-helix- $\beta 1-4$ loop) are involved in the interaction with luteolin 7,3'-disulfate. Residues Leu310 and Met378 are conservative among Chordata, and Ile379 is conservative among primates [38]. Notably, these structural elements were shown to interact with the elongated azole inhibitors (PDB ID: 3LD6, 4UHI and 6Q2T), suggesting that several residues of the active site are utilized for the distant binding of luteolin $7,3^{\prime}$-disulfate.

The docking pose obtained for luteolin 7,3'-disulfate showed binding in the access channel (Figure 4). Thus, the inhibition effect could be the result of blocking of the substrate access channel. However, the inhibition of CYP51A1 by luteolin 7,3'-disulfate does not exclude the modulation of interaction with its redox partner. The proximal surface of CYP51A1 - where the redox partner, cytochrome P450 reductase, is binding-contains positively charged amino acids which can interact with the negatively charged sulfate groups of luteolin $7,3^{\prime}$-disulfate.

\section{Discussion}

Plant flavonoids have a variety of biological activities in animals. However, despite numerous studies in this field, the mechanism/s of action of flavonoids remain poorly understood. Using animal models, it was shown that some flavonoids, luteolin in particular, may mitigate the toxicity of drugs [13,39]. However, the protective effect of flavonoids in humans has not been reliably ascertained [13]. There have been a number of studies reporting the effect of flavonoids, mostly on xenobiotic transformation by CYP enzymes and drug-drug interactions. In particular, baicalein showed an inhibition activity to CYP1A, CYP2B and CYP3A4, with IC50 values in the range of 0.5-36 $\mu \mathrm{M}[12,40]$. Both baicalein and luteolin inhibit diclofenac $4^{\prime}$-hydroxylase activity in the CYP2C9 RECO system, with baicalein acting as a competitive inhibitor of CYP2C9 [41]. The most effective luteolin inhibition was shown for CYP2C8, while its close homologs, CYP2C9 and CYP2C19, were less effectively inhibited [13]. The activity of CYP1A2, CYP3A, CYP2B6, CYP2E1 and CYP2D6 was also inhibited by luteolin, with an IC50 in the range of 1.6-132.6 $\mu \mathrm{M}[13,42]$. Notably, luteolin selectively inhibits CYP2D6-mediated metabolism with different substrates. For example, O-demethylation of 3-[2-(N,N-diethyl-N-methyl-ammonium)ethyl]-7-methoxy4-methylcoumarin was inhibited to $40 \%$ by the administration of $20 \mu \mathrm{M}$ luteolin, while the same concentration of luteolin showed less than a $5 \%$ inhibition in reaction with dextromethorphan [14]. Overall, the baicalein and luteolin inhibitory concentration on drug metabolizing CYPs is in the micromolar range.

The inhibition effect of flavonoids was also shown for CYPs involved in the biosynthesis of steroid hormones, neurosteroids, prostaglandins, as well as other regulatory metabolites. The effect of different flavonoids was evaluated on cortisol production in human adrenocortical H295R cells, and the competitive mechanism of inhibition was established for CYP21B1 [43]. The inhibition effect of luteolin was shown for human aromatase CYP19 [44]. A synthetic analogue of dihydrodaidzein, NV-52, inhibited the thromboxane A2 synthase CYP5A1 [45], while isoflavonoids inhibited the oxidation of vitamin D3 by CYP24A1 [46].

Sulfation, methylation and glucuronidation, occurring in the enterocytes and liver, are major factors affecting flavonoid bioavailability and are crucial for their transport via the blood [47]. Non-conjugated flavonoids are generally not present in plasma, however, there is an indication that a small amount of non-conjugated flavonoids can be transported through the blood system [48]. To the best of our knowledge, no studies have been conducted on the inhibition of CYP activity by sulfated forms of baicalein and luteolin. The inhibitory potential of other sulfated derivatives was probed with drug-metabolizing CYPs. It was shown that sulfated derivatives of quercetin and chrysin can inhibit several CYPs in vitro. In particular, quercetin $3^{\prime}$-sulfate has a selective concentration-dependent inhibition activity to CYP2C19 and CYP3A4 up to $30 \mu \mathrm{M}$, but the inhibition effect did 
not exceed $50 \%$ and overall was less than that of ticlopidine and ketoconazole (used as positive controls) [49]. Chrysin 7-sulfate has an IC50 value of $2.7 \mu \mathrm{M}$ to CYP2C9, which is comparable to that of the positive control sulfaphenazole [50]. Additionally, chrysin 7-sulfate showed a slight inhibition effect on CYP2C19 and CYP3A4 [50].

CYP51A1 is considered as a potent target for cholesterol-lowering drugs [51]. There is an indication that the regulation of CYP51A1 function could be important to the treatment of oncological pathologies [11]. It was shown that anticancer drugs, abiraterone and galeterone, which are steroidal inhibitors of CYP17A1, can interact with human CYP51A1. However, their inhibition potential was not estimated. The Kdapp values determined for the abiraterone and galeterone, were 22 and $16 \mu \mathrm{M}$, respectively [52], and are significantly higher than those for baicalein and luteolin obtained in this work $(8.2$ and $5.1 \mu \mathrm{M}$, respectively). In contrast, non-steroidal pyridine derivative LK-935 [53] and azole inhibitors, ketoconazole and econazole [38], have an affinity in the submicromolar range due to direct coordination with heme iron. However, azole derivatives have a poor bioavailability and relatively low selectivity which might cause adverse reactions.

We showed the inhibition of CYP51A1 activity by the sulfated derivative of luteolin isolated from seagrass within the family Zosteraceae (Zostera marina and Zostera asiatica). It was previously demonstrated that luteolin $7,3^{\prime}$-disulfate has a wide range of biological activities that might be linked to its higher bioavailability [33,54]. Considering that natural flavonoids and their biological activities are currently a subject of great interest and in light of our data, it is plausible to suggest that CYP51A1 activity could also be modulated by this group of compounds. Obtained data on inhibition by luteolin $7,3^{\prime}$-disulfate could be further explored for the development of a new class of CYP51A1 inhibitors.

\section{Materials and Methods}

\subsection{Samples}

Highly purified (>95\% by SDS-PAGE) recombinant human CYP51A1 protein was expressed and purified as previously described [38]. Low molecular weight compounds: lanosterol (PubChem CID 246983, CAS Number 79-63-0), natural substrate of CYP51A1, and ketoconazole (PubChem CID 456201, CAS Number 65277-42-1), azole inhibitor of CYP51A1, were obtained from Cayman Chemicals (Ann Arbor, MI, USA), baicalein (PubChem CID 5281605, CAS Number 491-67-8) was obtained from Sigma Aldrich (St. Louis, MO, USA), luteolin (PubChem CID 5280445, CAS Number 491-70-3) and luteolin 7,3'disulfate (PubChem CID 44258153) were purified in the G.B. Elyakov Pacific Institute of Bioorganic Chemistry (Vladivostok, Russia) by water-alcohol extraction, followed by chromatographic purification from the sea plants of Zosteraceae genus $[55,56]$.

\subsection{Surface Plasmon Resonance}

SPR analyses were carried out at $25{ }^{\circ} \mathrm{C}$ using the optical biosensors Biacore T200 and Biacore $8 \mathrm{~K}$ (GE Healthcare, Chicago, IL, USA) and sensor chips of CM5 series S type (Cytiva, Marlborough, MA, USA). HBS-N (10 mM HEPES, 150 mM NaCl, pH 7.4) (Cytiva) was used as a running buffer for CYP51A1 immobilization. Carboxyl groups of biosensor chip dextran were activated for $5 \mathrm{~min}$ by injection of the 1:1 mixture of 0.2 M 1-ethyl-3-(3-dimethylaminopropyl)carbodiimide hydrochloride (EDC) and $0.05 \mathrm{M}$ N-hydroxysuccinimide (NHS) at a flow rate of $5 \mu \mathrm{L} / \mathrm{min}$, followed by 1 min wash with HBS-N buffer at the same flow rate. Next, CYP51A1 $(25 \mu \mathrm{g} / \mathrm{mL})$ in $10 \mathrm{mM}$ sodium acetate ( $\mathrm{pH}$ 5.0) was injected into the working channel of the biosensor for $5 \mathrm{~min}$ at a flow rate of $5 \mu \mathrm{L} / \mathrm{min}$. The final level of immobilization was 13,500 RU (13.5 ng of protein). Reference channel without immobilized CYP51A1 was used to correct the effects of the non-specific binding of analytes to the chip surface.

Baicalein and luteolin were prepared as $10 \mathrm{mM}$ stock solutions in $100 \%$ dimethyl sulfoxide (DMSO). Experimental samples of baicalein and luteolin were prepared in an HBS-N buffer at the concentration range 10-100 $\mu \mathrm{M}$ and 1\% DMSO. The same amount of solvent was added to the HBS-N running buffer to minimize bulk-effects introduced by the 
difference between the refractive indexes of the running buffer and the experimental samples. Refractive indexes of running buffer and experimental samples were matched with a precision refractometer RX-5000 (Atago, Saitama, Japan). If needed, the concentration of solvent in the running buffer was corrected according to the equation:

$$
C(D M S O)_{\text {running buffer }}=C(D M S O)_{\text {sample }} \times \frac{\eta_{1}-\eta_{2}}{\eta_{3}-\eta_{2}},
$$

where $C(D M S O)_{\text {running buffer - DMSO final concentration in running buffer, } C(D M S O)_{\text {sample }}}$ -DMSO concentration in experimental sample, $\eta_{1}$-analyzed sample refractive index, $\eta_{2}-$ HBS-N buffer refractive index, $\eta_{3}$ - HBS-N buffer containing the DMSO of the same concentration as experimental sample refractive index.

Luteolin 7,3'-disulfate $10 \mathrm{mM}$ stock solution and experimental samples at final concentrations of 10-100 $\mu \mathrm{M}$ were prepared with HBS-N buffer without organic solvent. The same buffer was used as a running buffer with luteolin $7,3^{\prime}$-disulfate to minimize the bulk-effects on the obtained experimental data. A total of $10 \mathrm{mM}$ stock solution of lanosterol was prepared in ethanol. Lanosterol experimental samples at the final concentrations of 10-100 $\mu \mathrm{M}$, as well as the running buffer, were prepared by the same protocol as for baicalein and luteolin but in ethanol instead of DMSO.

Low molecular weight compounds were injected through biosensor channels (working and reference) at a flow rate of $10 \mu \mathrm{L} / \mathrm{min}$ (luteolin 7,3'-disulfate) and $50 \mu \mathrm{L} / \mathrm{min}$ (baicalein and luteolin) for $6 \mathrm{~min}$. Dissociation of the formed CYP51A1/compound complexes were registered at the same flow rate for no less than $6 \mathrm{~min}$ after the sample injection. After each biosensor cycle, a bound analyte was removed with two-times injection of regenerating solution ( $2 \mathrm{M} \mathrm{NaCl}, 1 \% \mathrm{CHAPS}$ ) at a flow rate of $30 \mu \mathrm{L} / \mathrm{min}$ for $30 \mathrm{~s}$.

SPR sensorgrams were processed in Biacore T200 Evaluation Software v.1.0 (GE Healthcare) and BIAevaluation Software v 4.1.1 (GE Healthcare) using "1:1 (Langmuir) binding" and "Two-state (conformational change) binding" data processing models. The 1:1 (Langmuir) binding model is a model for the 1:1 interaction between compound (C) with immobilized protein $(\mathrm{P})$, and is equivalent to the Langmuir isotherm for adsorption to a surface: $\mathrm{C}+\mathrm{P} \leftrightarrow \mathrm{CP}$. Two-state (conformational change) binding model describes a 1:1 binding of compound $(\mathrm{C})$ to immobilized protein $(\mathrm{P})$ followed by a conformational change in the complex $\left(\mathrm{CP} \leftrightarrow \mathrm{CP}^{*}\right)$. It is assumed that the conformationally changed complex can dissociate only through the reverse of the conformational change: $\mathrm{C}+\mathrm{P} \leftrightarrow \mathrm{CP} \leftrightarrow \mathrm{CP}$. The final kinetic parameters were obtained from the models with best fit of the experimental curves according to the minimum of the obtained $\mathrm{chi}^{2}$ value. The equations describing used models are as follows:

(1) 1:1 (Langmuir) binding [57]: $K_{d}=\frac{k_{o f f}}{k_{o n}}$, where $K_{d}$-equilibrium dissociation constant, $k_{o f f}$-dissociation rate constant, $k_{o n}$-association rate constant.

(2) Two-state (conformational change) binding [58]: $K_{d}=\frac{k_{o f f 1}}{k_{o n 1}} \times\left(1+\frac{k_{o n 2}}{k_{o f f 2}}\right)^{-1}$, where $K_{d}$ equilibrium dissociation constant, $k_{o f f 1}$-dissociation rate constant, $k_{\text {on } 1}$-association rate constant, $k_{\text {on } 2}$-forward rate constant for $\mathrm{CP} \leftrightarrow \mathrm{CP}^{*}$ transition, $k_{\text {off } 2}$-backward rate constant for $\mathrm{CP} \leftrightarrow \mathrm{CP}^{*}$ transition.

\subsection{Spectral Titration Analysis}

Spectrophotometric titration was used to determine the apparent dissociation constants $\left(K_{\text {dapp }}\right)$ for the enzyme-ligand complexes. The spectral measurements were performed on Cary Series UV-Vis-NIR (Agilent Technologies, Santa Clara, CA, USA) spectrophotometer using tandem quartz cuvettes $(1 \mathrm{~cm}$ optical path) to exclude the absorption of ligands. Natural substrate, lanosterol, at final concentration $5 \mu \mathrm{M}$ was added before the titration to the CYP51A1 (final concentration $4 \mu \mathrm{M}$ ) in $50 \mathrm{mM}$ potassium phosphate buffer, pH 7.4. For titration, the ligand solution was added to the experimental cuvette (baicalein and luteolin 7,3'-disulfate were added up to a final concentration of $30 \mu \mathrm{M}$, luteolin was added up to a final concentration of $15 \mu \mathrm{M}$ ) and an equal volume of solvent 
was added to the control cuvette. The difference spectra were recorded after each addition of ligand at room temperature in the range of $350-500 \mathrm{~nm}$. The apparent dissociation constants were determined by plotting the absorbance changes in the difference spectra versus the concentration of free ligand and evaluated by using the Hill equation (OriginPro 8.1 statistical data analysis package):

$$
A_{o b s}=A_{\max } \times\left(\frac{S \times n}{K_{\text {dapp }} \times n+S \times n}\right),
$$

where $A_{o b s}$-the observed change in the absorption, $A_{\max }$-the absorbance change at ligand saturation, $K_{\text {dapp }}$-the apparent dissociation constant for the ligand-enzyme complex, $S$ - the ligand concentration, $n$ - a Hill coefficient.

\subsection{Enzyme Assay}

Lanosterol 14-alpha-demethylase activity of human CYP51A1 was determined at $37^{\circ} \mathrm{C}$ in $50 \mathrm{MM} \mathrm{KPB}, 4 \mathrm{mM} \mathrm{MgCl} 2,0.1 \mathrm{mM}$ DTT in presence of lipids $(0.15 \mathrm{Mg} / \mathrm{mL}$ mixture 1:1:1 of L- $\alpha$-dilauroyl-sn-glycero-3-phosphocholine, L- $\alpha$-dioleoyl-sn-glycero-3-phosphocholine and L- $\alpha$-phosphatidyl-L-serine). The final concentrations of CYP51A1 and CPR were 0.5 and $2.0 \mu \mathrm{M}$, respectively. Aliquots of concentrated recombinant proteins were mixed and preincubated for $5 \mathrm{~min}$ at room temperature. Lanosterol ( $10 \mathrm{mM}$ stock solution in ethanol) was added to the reaction mixture at a final concentration of $50 \mu \mathrm{M}$. Tested compounds were added to the reaction mixture at a final concentration of $25 \mu \mathrm{M}$. To estimate the apparent IC50, the following concentrations of luteolin 7,3'-disulfate were used: 5, 10, 25, 50 and $100 \mu \mathrm{M}$. Ketoconazole at a concentration of $5 \mu \mathrm{M}$ was used as a positive control. After 10 min of preincubation at $37^{\circ} \mathrm{C}$, the reaction was started by adding NADPH at a final concentration of $0.25 \mathrm{mM}$. Aliquots $(0.5 \mathrm{~mL})$ were taken from the incubation mixture at chosen time intervals. Steroids were extracted with $5 \mathrm{~mL}$ of ethyl acetate. The mixture was vigorously mixed, the water and organic phases were separated by centrifugation at $3000 \mathrm{rpm}$ for $10 \mathrm{~min}$. The organic layer was carefully removed and dried under argon flow. A total of $50 \mu \mathrm{L}$ of methanol was added to the pellet and steroids were analyzed on a computerized Agilent 1200 series HPLC instrument (Agilent Technologies, USA) equipped with Agilent Triple Quad 6410 mass spectrometer (Agilent Technologies). Samples were analyzed by gradient elution on Zorbax Eclipse XDB C18 column $(4.6 \times 150 \mathrm{~mm} ; 5 \mu \mathrm{m})$ (Agilent Technologies). A total of $0.1 \%(v / v)$ FA in water was used as the mobile phase A and $0.1 \%(v / v)$ FA in methanol:1-propanol mix $(75: 25, v / v)$ as mobile phase B. The gradient was $75-100 \%$ B in $0-5 \mathrm{~min}$. The flow rate was $500 \mu \mathrm{L}$ per min. The column temperature was maintained at $40 \pm 1{ }^{\circ} \mathrm{C}$. Mass spectrometry experiments were performed with atmospheric pressure chemical ionization source (APCI) at positive ion mode. The following APCI settings were used: gas temperature $200{ }^{\circ} \mathrm{C}$, vaporizer $250{ }^{\circ} \mathrm{C}$, gas flow $7 \mathrm{~L} / \mathrm{min}$, nebulizer pressure $40 \mathrm{psig}$, Vcap $4000 \mathrm{~V}$, corona $4 \mu \mathrm{A}$, fragmentor $100 \mathrm{~V}$. The data acquisition mode was MS2Scan from 200 to $550 \mathrm{Da}$.

\subsection{Molecular Docking}

Crystal structure of CYP51A1 PDB ID 3LD6 was used for docking. 3D structures of luteolin (CID 5280445) and luteolin 7,3'-disulfate (CID 44258153) were obtained from the PubChem database (https:/ / pubchem.ncbi.nlm.nih.gov/, accessed on 7 November 2020). Removal of water and ligand molecules from the original protein PDB files and molecular docking over the entire surface of CYP51A1 were performed automatically in the Flare software package (Cresset, Litlington, UK) with default settings [59]. Docking hypotheses were arranged according to score functions values: Lead Finder (LF) Rank Score, LF dG, LF VSscore. The lower is the LF Rank Score, the higher is the likelihood that the docked pose reproduces the crystallographic pose. LF dG has been designed to perform accurate estimation of the free energy of protein-ligand binding for a given protein-ligand complex. LF VSscore has been designed to produce maximum efficiency in 
virtual screening experiments, i.e., to assign higher scores to active ligands (true binders) and lower scores to inactive ligands. Molecular graphics visualization tool Maestro version 12.5.139 (Schrödinger, New York, NY, USA) was used to analyze the selected docking hypotheses.

\title{
5. Conclusions
}

In this work, we identified a new ligand of human CYP51A1 among natural flavonoidluteolin 7,3'-disulfate-that inhibits $14 \alpha$-demethylase activity. Potential inhibitory mechanisms include blocking of either a substrate access channel or the interaction with a redox partner. Obtained results suggest further exploration of polyphenols for the cholesterol lowering ability and anti-cancer potential via CYP51A1.

\begin{abstract}
Author Contributions: Conceptualization, L.K., P.E. and E.Y.; methodology, L.K., P.E. and E.Y.; formal analysis, L.K., P.E., T.S., P.S., S.F., I.G. and A.G.; investigation, L.K., P.E., E.Y., Y.M. and O.G.; resources, T.S., S.U., A.P., A.A., O.S. and N.S.; data curation, L.K., P.E. and E.Y.; writing-original draft preparation, P.E.; writing-review and editing, L.K., P.E., E.Y., Y.M., O.G., A.G. and N.S.; visualization, L.K., P.E. and E.Y.; supervision, N.S.; project administration, A.I. All authors have read and agreed to the published version of the manuscript.
\end{abstract}

Funding: Surface plasmon resonance analysis was funded by the Russian Foundation for Basic Research (grant № 20-04-00014) and was performed using the equipment of "Human Proteome" Core Facility of the Institute of Biomedical Chemistry supported by MINOBRNAUKI, Agreement № 075-15-2019-1502 from 5 September 2019. Catalytic activity analysis was funded by SPSR of Belarus "Chemical processes, reagents and technologies, bioregulators and bioorganic chemistry", (project 2.3.1.1). Spectral titration analysis and molecular docking simulations were done in the framework of the Russian Federation fundamental research program for the long-term period for 2021-2030.

Institutional Review Board Statement: Not applicable.

Informed Consent Statement: Not applicable.

Data Availability Statement: Datasets are available from the authors.

Conflicts of Interest: The authors declare no conflict of interest.

Sample Availability: Samples of the compounds are available from the authors.

\section{References}

1. Porter, J.A.; Young, K.E.; Beachy, P.A. Cholesterol Modification of Hedgehog Signaling Proteins in Animal Development. Science 1996, 274, 255-259. [CrossRef] [PubMed]

2. Xiao, X.; Tang, J.-J.; Peng, C.; Wang, Y.; Fu, L.; Qiu, Z.-P.; Xiong, Y.; Yang, L.-F.; Cui, H.-W.; He, X.-L.; et al. Cholesterol Modification of Smoothened Is Required for Hedgehog Signaling. Mol. Cell 2017, 66, 154-162.e10. [CrossRef] [PubMed]

3. McNeill, A.M.; Rosamond, W.D.; Girman, C.J.; Golden, S.H.; Schmidt, M.I.; East, H.E.; Ballantyne, C.M.; Heiss, G. The Metabolic Syndrome and 11-Year Risk of Incident Cardiovascular Disease in the Atherosclerosis Risk in Communities Study. Diabetes Care 2005, 28, 385-390. [CrossRef]

4. Kumarakulasingham, M.; Rooney, P.H.; Dundas, S.R.; Telfer, C.; Melvin, W.T.; Curran, S.; Murray, G.I. Cytochrome P450 Profile of Colorectal Cancer: Identification of Markers of Prognosis. Clin. Cancer Res. 2005, 11, 3758-3765. [CrossRef] [PubMed]

5. Aoyama, Y. Recent Progress in the CYP51 Research Focusing on Its Unique Evolutionary and Functional Characteristics as a Diversozyme P450. Front. Biosci. 2005, 10, 1546-1557. [CrossRef] [PubMed]

6. Murray, G.I.; Patimalla, S.; Stewart, K.N.; Miller, I.D.; Heys, S.D. Profiling the Expression of Cytochrome P450 in Breast Cancer. Histopathology 2010, 57, 202-211. [CrossRef]

7. Sun, M.; Qiu, J.; Zhai, H.; Wang, Y.; Ma, P.; Li, M.; Chen, B. Prognostic Implications of Novel Gene Signatures in Gastric Cancer Microenvironment. Med. Sci. Monit. 2020, 26, e924604-1-e924604-17. [CrossRef] [PubMed]

8. Gabitova, L.; Restifo, D.; Gorin, A.; Manocha, K.; Handorf, E.; Yang, D.-H.; Cai, K.Q.; Klein-Szanto, A.J.; Cunningham, D.; Kratz, L.E.; et al. Endogenous Sterol Metabolites Regulate Growth of EGFR/KRAS-Dependent Tumors via LXR. Cell Rep. 2015, 12, 1927-1938. [CrossRef]

9. Salmina, K.; Huna, A.; Kalejs, M.; Pjanova, D.; Scherthan, H.; Cragg, M.S.; Erenpreisa, J. The Cancer Aneuploidy Paradox: In the Light of Evolution. Genes 2019, 10, 83. [CrossRef]

10. Keber, R.; Motaln, H.; Wagner, K.D.; Debeljak, N.; Rassoulzadegan, M.; Ačimovič, J.; Rozman, D.; Horvat, S. Mouse Knockout of the Cholesterogenic Cytochrome P450 Lanosterol 14alpha-Demethylase (Cyp51) Resembles Antley-Bixler Syndrome. J. Biol. Chem. 2011, 286, 29086-29097. [CrossRef] 
11. Martínez-Botas, J.; Ferruelo, A.J.; Suárez, Y.; Gómez-Coronado, D.; Lasunción, M.A. Induction of Apoptosis in P53-Null HL-60 Cells by Inhibition of Lanosterol 14-Alpha Demethylase. Biochimie 1998, 80, 887-894. [CrossRef]

12. Noh, K.; Nepal, M.R.; Jeong, K.S.; Kim, S.-A.; Um, Y.J.; Seo, C.S.; Kang, M.J.; Park, P.-H.; Kang, W.; Jeong, H.G.; et al. Effects of Baicalin on Oral Pharmacokinetics of Caffeine in Rats. Biomol. Ther. 2015, 23, 201-206. [CrossRef] [PubMed]

13. Cao, L.; Kwara, A.; Greenblatt, D.J. Metabolic Interactions between Acetaminophen (Paracetamol) and Two Flavonoids, Luteolin and Quercetin, through in-Vitro Inhibition Studies. J. Pharm. Pharmacol. 2017, 69, 1762-1772. [CrossRef] [PubMed]

14. Fliszár-Nyúl, E.; Mohos, V.; Csepregi, R.; Mladěnka, P.; Poór, M. Inhibitory Effects of Polyphenols and Their Colonic Metabolites on CYP2D6 Enzyme Using Two Different Substrates. Biomed. Pharmacother. 2020, 131, 110732. [CrossRef] [PubMed]

15. Da, X.; Nishiyama, Y.; Tie, D.; Hein, K.Z.; Yamamoto, O.; Morita, E. Antifungal Activity and Mechanism of Action of Ou-Gon (Scutellaria Root Extract) Components against Pathogenic Fungi. Sci. Rep. 2019, 9, 1683. [CrossRef] [PubMed]

16. Huang, S.; Cao, Y.Y.; Dai, B.D.; Sun, X.R.; Zhu, Z.Y.; Cao, Y.B.; Wang, Y.; Gao, P.H.; Jiang, Y.Y. In Vitro Synergism of Fluconazole and Baicalein against Clinical Isolates of Candida Albicans Resistant to Fluconazole. Biol. Pharm. Bull. 2008, 31, 2234-2236. [CrossRef]

17. Joung, D.-K.; Lee, Y.-S.; Han, S.-H.; Lee, S.-W.; Cha, S.-W.; Mun, S.-H.; Kong, R.; Kang, O.-H.; Song, H.-J.; Shin, D.-W.; et al. Potentiating Activity of Luteolin on Membrane Permeabilizing Agent and ATPase Inhibitor against Methicillin-Resistant Staphylococcus Aureus. Asian Pac. J. Trop. Med. 2016, 9, 19-22. [CrossRef]

18. Popov, A.M.; Osipov, A.N.; Korepanova, E.A.; Krivoshapko, O.N.; Artyukov, A.A.; Klimovich, A.A. A Study of the Antioxidant and Membranotropic Activities of Luteolin Using Different Model Systems. BIOPHYSICS 2016, 61, 843-850. [CrossRef]

19. Ravishankar, D.; Watson, K.A.; Boateng, S.Y.; Green, R.J.; Greco, F.; Osborn, H.M.I. Exploring Quercetin and Luteolin Derivatives as Antiangiogenic Agents. Eur. J. Med. Chem. 2015, 97, 259-274. [CrossRef]

20. Gao, Y.; Snyder, S.A.; Smith, J.N.; Chen, Y.C. Anticancer Properties of Baicalein: A Review. Med. Chem. Res. 2016, 25, 1515-1523. [CrossRef]

21. Imran, M.; Rauf, A.; Abu-Izneid, T.; Nadeem, M.; Shariati, M.A.; Khan, I.A.; Imran, A.; Orhan, I.E.; Rizwan, M.; Atif, M.; et al. Luteolin, a Flavonoid, as an Anticancer Agent: A Review. Biomed. Pharmacother. 2019, 112, 108612. [CrossRef] [PubMed]

22. Tuli, H.S.; Aggarwal, V.; Kaur, J.; Aggarwal, D.; Parashar, G.; Parashar, N.C.; Tuorkey, M.; Kaur, G.; Savla, R.; Sak, K.; et al. Baicalein: A Metabolite with Promising Antineoplastic Activity. Life Sci. 2020, 259, 118183. [CrossRef] [PubMed]

23. Shen, J.; Li, P.; Liu, S.; Liu, Q.; Li, Y.; Sun, Y.; He, C.; Xiao, P. Traditional Uses, Ten-Years Research Progress on Phytochemistry and Pharmacology, and Clinical Studies of the Genus Scutellaria. J. Ethnopharmacol. 2021, 265, 113198. [CrossRef] [PubMed]

24. Nik Salleh, N.N.H.; Othman, F.A.; Kamarudin, N.A.; Tan, S.C. The Biological Activities and Therapeutic Potentials of Baicalein Extracted from Oroxylum Indicum: A Systematic Review. Molecules 2020, 25, 5677. [CrossRef]

25. Farooqi, A.A.; Butt, G.; El-Zahaby, S.A.; Attar, R.; Sabitaliyevich, U.Y.; Jovic, J.J.; Tang, K.-F.; Naureen, H.; Xu, B. Luteolin Mediated Targeting of Protein Network and MicroRNAs in Different Cancers: Focus on JAK-STAT, NOTCH, MTOR and TRAIL-Mediated Signaling Pathways. Pharmacol. Res. 2020, 160, 105188. [CrossRef] [PubMed]

26. Tuorkey, M.J. Molecular Targets of Luteolin in Cancer. Eur. J. Cancer Prev. 2016, 25, 65-76. [CrossRef] [PubMed]

27. Barreca, D.; Mandalari, G.; Calderaro, A.; Smeriglio, A.; Trombetta, D.; Felice, M.R.; Gattuso, G. Citrus Flavones: An Update on Sources, Biological Functions, and Health Promoting Properties. Plants 2020, 9, 288. [CrossRef]

28. Zhou, Y.; Zheng, J.; Li, Y.; Xu, D.-P.; Li, S.; Chen, Y.-M.; Li, H.-B. Natural Polyphenols for Prevention and Treatment of Cancer. Nutrients 2016, 8. [CrossRef]

29. Harborne, J.B.; Williams, C.A. Occurrence of Sulphated Flavones and Caffeic Acid Esters in Members of the Fluviales. Biochem. Syst. Ecol. 1976, 4, 37-41. [CrossRef]

30. Popov, A.M.; Krivoshapko, O.N.; Artyukov, A.A. Comparative estimation of pharmacological activities of luteolin and luteolin 7,3'-disulphate at modelling of different pathologies. Russ. J. Biopharm. 2011, 3, 27-33.

31. Klimovich, A.A.; Popov, A.M.; Styshova, O.N.; Artyukov, A.A.; Tsybulsky, A.V. A Comparative Evaluation of the Actions of Different Secondary Metabolites of Marine Hydrobionts on the Redox Status of Tumor and Immune Cells. Biophysics 2018, 63, 763-768. [CrossRef]

32. Kwak, J.Y.; Seok, J.K.; Suh, H.-J.; Choi, Y.-H.; Hong, S.S.; Kim, D.S.; Boo, Y.C. Antimelanogenic Effects of Luteolin 7-Sulfate Isolated from Phyllospadix Iwatensis Makino. Br. J. Dermatol. 2016, 175, 501-511. [CrossRef] [PubMed]

33. Popov, A.M.; Krivoshapko, O.N. Protective Effects of Polar Lipids and Redox-Active Compounds from Marine Organisms at Modeling of Hyperlipidemia and Diabetes. J. Biomed. Sci. Eng. 2013, 6, 543-550. [CrossRef]

34. Popov, A.M.; Krivoshapko, O.N.; Klimovich, A.A.; Artyukov, A.A. Biological activity and mechanisms of therapeutic action of rosmarinic acid, luteolin and its sulphated derivatives. Biomed. Khim. 2016, 62, 22-30. [CrossRef]

35. Kaluzhskiy, L.A.; Gnedenko, O.V.; Gilep, A.A.; Strushkevich, N.V.; Shkel, T.V.; Chernovetsky, M.A.; Ivanov, A.S.; Lisitsa, A.V.; Usanov, A.S.; Stonik, V.A.; et al. Screening of Human Cytochrome P450(51) (CYP51A1) Inhibitors: Structural Lanosterol Analogues of Plant and Animal Origin. Biochem. (Moscow) Suppl. B Biomed. Chem. 2014, 8, 349-360. [CrossRef]

36. Shimada, T.; Tanaka, K.; Takenaka, S.; Foroozesh, M.K.; Murayama, N.; Yamazaki, H.; Guengerich, F.P.; Komori, M. Reverse Type I Binding Spectra of Human Cytochrome P450 1B1 Induced by Flavonoid, Stilbene, Pyrene, Naphthalene, Phenanthrene, and Biphenyl Derivatives That Inhibit Catalytic Activity: A Structure-Function Relationship Study. Chem. Res. Toxicol. 2009, 22, 1325-1333. [CrossRef] [PubMed] 
37. Nitahara, Y.; Kishimoto, K.; Yabusaki, Y.; Gotoh, O.; Yoshida, Y.; Horiuchi, T.; Aoyama, Y. The Amino Acid Residues Affecting the Activity and Azole Susceptibility of Rat CYP51 (Sterol 14-Demethylase P450). J. Biochem. 2001, 129, 761-768. [CrossRef]

38. Strushkevich, N.; Usanov, S.A.; Park, H.-W. Structural Basis of Human CYP51 Inhibition by Antifungal Azoles. J. Mol. Biol. 2010, 397, 1067-1078. [CrossRef]

39. Yousef, M.I.; Omar, S.A.M.; El-Guendi, M.I.; Abdelmegid, L.A. Potential Protective Effects of Quercetin and Curcumin on Paracetamol-Induced Histological Changes, Oxidative Stress, Impaired Liver and Kidney Functions and Haematotoxicity in Rat. Food Chem. Toxicol. 2010, 48, 3246-3261. [CrossRef]

40. Cho, Y.-A.; Choi, J.-S.; Burm, J.-P. Effects of the Antioxidant Baicalein on the Pharmacokinetics of Nimodipine in Rats: A Possible Role of P-Glycoprotein and CYP3A4 Inhibition by Baicalein. Pharmacol. Rep. 2011, 63, 1066-1073. [CrossRef]

41. Si, D.; Wang, Y.; Zhou, Y.-H.; Guo, Y.; Wang, J.; Zhou, H.; Li, Z.-S.; Fawcett, J.P. Mechanism of CYP2C9 Inhibition by Flavones and Flavonols. Drug Metab. Dispos. 2009, 37, 629-634. [CrossRef]

42. Quintieri, L.; Palatini, P.; Nassi, A.; Ruzza, P.; Floreani, M. Flavonoids Diosmetin and Luteolin Inhibit Midazolam Metabolism by Human Liver Microsomes and Recombinant CYP 3A4 and CYP3A5 Enzymes. Biochem. Pharmacol. 2008, 75, 1426-1437. [CrossRef] [PubMed]

43. Ohno, S.; Shinoda, S.; Toyoshima, S.; Nakazawa, H.; Makino, T.; Nakajin, S. Effects of Flavonoid Phytochemicals on Cortisol Production and on Activities of Steroidogenic Enzymes in Human Adrenocortical H295R Cells. J. Steroid Biochem. Mol. Biol. 2002, 80, 355-363. [CrossRef]

44. Hodek, P.; Trefil, P.; Stiborová, M. Flavonoids-Potent and Versatile Biologically Active Compounds Interacting with Cytochromes P450. Chem.-Biol. Interact. 2002, 139, 1-21. [CrossRef]

45. Howes, L.G.; James, M.J.; Florin, T.; Walker, C. Nv-52: A Novel Thromboxane Synthase Inhibitor for the Treatment of Inflammatory Bowel Disease. Expert Opin. Investig. Drugs 2007, 16, 1255-1266. [CrossRef] [PubMed]

46. Swami, S.; Krishnan, A.V.; Peehl, D.M.; Feldman, D. Genistein Potentiates the Growth Inhibitory Effects of 1,25-Dihydroxyvitamin D3 in DU145 Human Prostate Cancer Cells: Role of the Direct Inhibition of CYP24 Enzyme Activity. Mol. Cell. Endocrinol. 2005, 241, 49-61. [CrossRef] [PubMed]

47. Thilakarathna, S.H.; Rupasinghe, H.P.V. Flavonoid Bioavailability and Attempts for Bioavailability Enhancement. Nutrients 2013, 5, 3367-3387. [CrossRef]

48. Williamson, G.; Manach, C. Bioavailability and Bioefficacy of Polyphenols in Humans. II. Review of 93 Intervention Studies. Am. J. Clin. Nutr. 2005, 81, 243S-255S. [CrossRef]

49. Mohos, V.; Fliszár-Nyúl, E.; Ungvári, O.; Kuffa, K.; Needs, P.W.; Kroon, P.A.; Telbisz, Á.; Özvegy-Laczka, C.; Poór, M. Inhibitory Effects of Quercetin and Its Main Methyl, Sulfate, and Glucuronic Acid Conjugates on Cytochrome P450 Enzymes, and on OATP, BCRP and MRP2 Transporters. Nutrients 2020, 12, 2306. [CrossRef]

50. Mohos, V.; Fliszár-Nyúl, E.; Ungvári, O.; Bakos, É.; Kuffa, K.; Bencsik, T.; Zsidó, B.Z.; Hetényi, C.; Telbisz, Á.; Özvegy-Laczka, C.; et al. Effects of Chrysin and Its Major Conjugated Metabolites Chrysin-7-Sulfate and Chrysin-7-Glucuronide on Cytochrome P450 Enzymes and on OATP, P-Gp, BCRP, and MRP2 Transporters. Drug Metab. Dispos. 2020, 48, 1064-1073. [CrossRef]

51. Monostory, K.; Pascussi, J.-M.; Szabó, P.; Temesvári, M.; Köhalmy, K.; Acimovic, J.; Kocjan, D.; Kuzman, D.; Wilzewski, B.; Bernhardt, R.; et al. Drug Interaction Potential of 2-((3,4-Dichlorophenethyl)(Propyl)Amino)-1-(Pyridin-3-Yl)Ethanol (LK-935), the Novel Nonstatin-Type Cholesterol-Lowering Agent. Drug Metab. Dispos. 2009, 37, 375-385. [CrossRef]

52. Masamrekh, R.; Kuzikov, A.; Veselovsky, A.; Toropygin, I.; Shkel, T.; Strushkevich, N.; Gilep, A.; Usanov, S.; Archakov, A.; Shumyantseva, V. Interaction of 17 $\alpha$-Hydroxylase, 17(20)-Lyase (CYP17A1) Inhibitors-Abiraterone and Galeterone-with Human Sterol 14 $\alpha$-Demethylase (CYP51A1). J. Inorg. Biochem. 2018, 186, 24-33. [CrossRef]

53. Korošec, T.; Ačimovič, J.; Seliškar, M.; Kocjan, D.; Tacer, K.F.; Rozman, D.; Urleb, U. Novel Cholesterol Biosynthesis Inhibitors Targeting Human Lanosterol 14 $\alpha$-Demethylase (CYP51). Bioorg. Med. Chem. 2008, 16, 209-221. [CrossRef] [PubMed]

54. Artjukov, A.A.; Kozlovskaja, E.P.; Krivoshapko, O.N.; Krylova, N.V.; Leonova, G.N.; Popov, A.M. Medication, Possessing Antioxidant, Cardioprotective, Antidiabetic, Anti-Inflammatory, Hepatoprotective, Antitumoral and Antiviral Action 2011. Russian Federation Patent № RU2432959C1, 10 November 2011.

55. Kim, J.H.; Cho, Y.H.; Park, S.M.; Lee, K.E.; Lee, J.J.; Lee, B.C.; Pyo, H.B.; Song, K.S.; Park, H.D.; Yun, Y.P. Antioxidants and Inhibitor of Matrix Metalloproteinase-1 Expression from Leaves of Zostera Marina L. Arch. Pharm. Res. 2004, 27, 177-183. [CrossRef] [PubMed]

56. Artjukov, A.A.; Glazunov, V.P.; Kochergina, T.J.; Kozlovskaja, E.P.; Kupera, E.V.; Makhan'kov, V.V.; Novikov, V.L.; Rutskova, T.A. Method of Obtaining Luteolyn 7,3'-Disulphate 2011. Russian Federation Patent № RU2432960C1, 10 November 2011.

57. Müller, K.M.; Arndt, K.M.; Plückthun, A. Model and Simulation of Multivalent Binding to Fixed Ligands. Anal. Biochem 1998, 261, 149-158. [CrossRef] [PubMed]

58. Lipschultz, C.A.; Li, Y.; Smith-Gill, S. Experimental Design for Analysis of Complex Kinetics Using Surface Plasmon Resonance. Methods 2000, 20, 310-318. [CrossRef] [PubMed]

59. Cheeseright, T.; Mackey, M.; Rose, S.; Vinter, A. Molecular Field Extrema as Descriptors of Biological Activity: Definition and Validation. J. Chem. Inf. Model. 2006, 46, 665-676, . [CrossRef] 